\title{
Multisystem Inflammatory Syndrome in Children (MIS-C) Associated with 2019 Novel Coronavirus (SARS-CoV-2) Infection
}

\author{
Helen Kest ${ }^{D},{ }^{1}$ Ashlesha Kaushik, ${ }^{2}$ William DeBruin, ${ }^{3}$ Mario Colletti, ${ }^{3}$ \\ and David Goldberg ${ }^{1}$ \\ ${ }^{1}$ Pediatric Infectious Disease, Department of Pediatrics, St. Joseph's Children's Hospital, Paterson, \\ NJ 07503, USA \\ ${ }^{2}$ Pediatric Infectious Diseases, Unity Point Health, University of Iowa, Carver College of Medicine, 2720 Stone Park Blvd, \\ Sioux City, IA 51104, USA \\ ${ }^{3}$ Pediatric Intensive Care Unit, Department of Pediatrics, St. Joseph's Children's Hospital, Paterson, NJ 07503, USA \\ Correspondence should be addressed to Helen Kest; kesth@sjhmc.org
}

Received 27 May 2020; Accepted 23 June 2020; Published 18 July 2020

Academic Editor: Maria Moschovi

Copyright (c) 2020 Helen Kest et al. This is an open access article distributed under the Creative Commons Attribution License, which permits unrestricted use, distribution, and reproduction in any medium, provided the original work is properly cited.

\begin{abstract}
We report three critically ill pediatric patients (aged 6-10 years), presenting with features of multisystem inflammatory syndrome in children (MIS-C) from April 4 to May 10, 2020, to a tertiary-care center in New Jersey, United States. All patients tested positive for severe acute respiratory syndrome coronavirus 2 (SARS-CoV-2) infection and were previously healthy. Clinical presentations were similar with fever, abdominal pain, gastrointestinal complaints, and/or rash. One patient had altered mental status with cerebrospinal fluid (CSF) findings consistent with aseptic meningitis. Laboratory values were remarkable for high levels of C-reactive protein, D-dimers, B-type natriuretic peptide (BNP), and troponin in all patients. All had low albumin levels. Evaluation for other infectious etiologies was negative. All of the patients were critically ill, requiring admission to the intensive care unit. All had circulatory shock and needed inotropes. Two patients had respiratory failure requiring advanced respiratory support and one had cardiac dysfunction. All patients received steroids, and two received intravenous immunoglobulin (IVIG). One patient received tocilizumab. None of the children died. MIS-C is a recently recognized pediatric illness spectrum in association with SARS-CoV-2 infection, and clinical characterization is essential for understanding disease mechanisms to inform clinical practice.
\end{abstract}

\section{Introduction}

We are in the midst of an unprecedented global pandemic of coronavirus disease (COVID-19), caused by the novel coronavirus SARS-CoV-2. Initially thought to affect children less severely [1-3], SARS-CoV-2 infection has recently been associated with a novel set of clinical manifestations presently called multisystem inflammatory syndrome in children (MIS-C) [4] that is beginning to be recognized in the United States, although published reports from the United States are lacking. We describe three critically ill patients with the spectrum of MIS-C associated with SARS$\mathrm{CoV}-2$ infection presenting to a tertiary-care center in New Jersey.

\section{Case 1}

A 10-year-old female with no significant past medical history presented following four days of febrile illness (fever to $105^{\circ} \mathrm{F}$ ), associated with progressively worsening diffuse abdominal pain and multiple episodes (4-5 times per day) of watery, nonbloody, nonmucoid stools. One day prior to presentation, she developed pink eyes and generalized rash. There was associated lethargy but no report of chest pain, shortness of breath, or vomiting. There were no sick contacts. Upon presentation to the pediatric emergency department (ED), the patient was noted to be lethargic and febrile, with a temperature of $38.8^{\circ} \mathrm{C}$ and heart rate of 144 beats per minute. Oxygen saturation and blood pressure 
were normal. Physical examination was remarkable for conjunctival injection, a generalized blanching rash, and diffuse abdominal tenderness. Four hours after admission, she became hypotensive (blood pressure of $82 / 43 \mathrm{mmHg}$ ) needing multiple fluid boluses and inotropic support with norepinephrine. Blood and urine cultures were obtained and were negative. The patient was noted to have neutrophilia, lymphopenia, hypoalbuminemia, elevated ESR (erythrocyte sedimentation rate), CRP (C-reactive protein), fibrinogen, $\mathrm{D}$-dimers, ferritin, troponin, and B-type natriuretic peptide (BNP). Clinical characteristics and laboratory evaluation are summarized in Table 1.

Additionally, the patient had a negative respiratory viral panel (RVP). SARS-CoV-2 RT-PCR (reverse-transcription polymerase chain reaction) was positive. She received intravenous antibiotics (ceftriaxone and linezolid) for a total of 2 days until blood, urine, and stool cultures were negative. Imaging studies were unremarkable (Table 1). She received IVIG (intravenous immunoglobulin at $2 \mathrm{~g} / \mathrm{Kg}$ ), steroids, and enoxaparin for treatment and was discharged home after 6 days of hospital stay.

\section{Case 2}

A 6-year-old female with no significant past medical history presented with fever up to $39^{\circ} \mathrm{C}$ for four days with associated headaches, vomiting, abdominal pain, diarrhea, conjunctivitis, and rash. She had exposure to grandfather with COVID-19 two weeks earlier. At admission, she had a temperature of $40^{\circ} \mathrm{C}$, heart rate of 138 beats per minute, respiratory rate of 24 breaths per minute, and oxygen saturation of $100 \%$ on room air. Two hours later, she was noted to be febrile to $40^{\circ} \mathrm{C}$ and hypotensive with blood pressure of $70 / 40 \mathrm{mmHg}$ requiring pressor support and developed respiratory failure needing intubation and mechanical ventilation. The patient was noted to have lymphopenia, thrombocytopenia, hypoalbuminemia, elevated levels of inflammatory markers, D-dimers, ferritin, troponin, and BNP as shown in Table 1 . The patient had a negative respiratory viral panel (RVP) and SARS-CoV-2 PCR. Antibody testing for SARS-CoV-2 (SARS-CoV-2 IgG) was positive.

The patient received broad spectrum intravenous antibiotics (meropenem and linezolid), IVIG $(2 \mathrm{~g} / \mathrm{kg})$, methylprednisolone, and enoxaparin. However, due to pulmonary edema and increased oxygen requirements, she was treated with tocilizumab (one dose of $12 \mathrm{mg} / \mathrm{kg}$ ) on day 4 of hospitalization. She was extubated on day 9 of hospitalization and gradually weaned off oxygen. She was discharged after a hospital stay of 14 days.

\section{Case 3}

A 9-year-old previously healthy male presented with 4 days of febrile illness (to $38.2^{\circ} \mathrm{C}$ ) with alerted mental status, diarrhea, vomiting, conjunctivitis, shortness of breath, and facial swelling. He was admitted to the pediatric intensive care unit (PICU) and intubated for hypoxic respiratory failure. An echocardiogram showed borderline low systolic function with a shortening fraction of $29-30 \%$. He was treated with dopamine and milrinone and required respiratory support with bilevel positive airway pressure (BiPAP). The patient was noted to have leukocytosis, neutrophilia, and hypoalbuminemia, with elevated levels of troponin and BNP (Table 1). The cerebrospinal fluid (CSF) findings were consistent with aseptic meningitis (white cell-count of 100/ $\mu \mathrm{L}$ with $52 \%$ lymphocytes, $36 \%$ monocytes, a normal glucose of $84 \mathrm{mg} / \mathrm{dL}$ (normal range 50 to $75 \mathrm{mg} / \mathrm{dL}$ ), and protein of $31 \mathrm{mg} / \mathrm{dL}$ (normal range $15-45 \mathrm{mg} / \mathrm{dL}$ ). The patient had a negative respiratory viral panel (RVP) and a positive SARSCoV-2 RT-PCR.

The hospital course was complicated by impairment of kidney function manifested by high serum creatinine which resolved with hydration. The patient was treated with broadspectrum intravenous antibiotics (ceftriaxone and linezolid) as well as hydroxychloroquine, methylprednisolone, and enoxaparin. He became afebrile on day 3 of hospitalization. Blood, CSF, and urine cultures were negative. Testing for Lyme, Mycoplasma pneumoniae, cytomegalovirus (CMV), West Nile virus, and Epstein Barr virus (EBV) were all negative.

\section{Discussion}

This is the first report of multisystem inflammatory syndrome in children (MIS-C) associated with SARS-CoV-2 infection in New Jersey in three hospitalized patients from April 4 to May 10, 2020. All patients (aged 6-10 years) were previously healthy, over $50^{\text {th }}$ centile for weight with no comorbidities, who developed multiorgan involvement and systemic inflammation leading to critical illness needing intensive care.

MIS-C is a newly recognized spectrum of disease manifestations in children associated with novel coronavirus SARS-CoV-2 infection [4]. MIS-C appears to exclusively affect children and has been recently recognized with few published international reports [5-7]. Features of Kawasaki disease- (KD-) like illness were first described in children with 2019 coronavirus disease (COVID-19) in the United Kingdom (UK) in late April and a recent study reported children with cardiac involvement and shock of whom one died $[5,6]$. The study from Italy also described KD-like features in children with SARS-CoV-2 infection [7]. The condition is being recently recognized in the United States; however, there is lack of published reports in the US. The Centers for Disease Control and Prevention (CDC) has declared MIS-C to be a reportable illness as of May 14, 2020, and has recently provided a case definition which includes patients under 21 years of age with fever $\left(>38.0^{\circ} \mathrm{C}\right.$ for $\geq 24$ hours, or report of subjective fever lasting $\geq 24$ hours), laboratory evidence of inflammation [one or more of the following: elevated C-reactive protein (CRP), erythrocyte sedimentation rate (ESR), fibrinogen, procalcitonin, $D$-dimer, ferritin, lactic acid dehydrogenase (LDH), or interleukin 6 (IL6), elevated neutrophils, reduced lymphocytes, and low albumin)], severe illness needing hospitalization, and involvement of two or more organ systems (cardiac, renal, respiratory, hematologic, gastrointestinal, dermatologic, or 
TABLE 1: Clinical characteristics of patients.

\begin{tabular}{|c|c|c|c|}
\hline & Patient 1 & Patient 2 & Patient 3 \\
\hline \multicolumn{4}{|l|}{ Patient characteristics } \\
\hline Age (years) & 10 & 6 & 9 \\
\hline Sex & Female & Female & Male \\
\hline Race & White Hispanic & White Hispanic & African American \\
\hline Time to presentation & 4 days & 4 days & 4 days \\
\hline $\begin{array}{l}\text { SARS-CoV-2 testing (RT- } \\
\text { PCR) }\end{array}$ & Positive & $\begin{array}{l}\text { Negative RT-PCR; positive } \\
\text { SARS-CoV-2 IgG }\end{array}$ & Positive \\
\hline \multicolumn{4}{|l|}{ Laboratory values } \\
\hline $\begin{array}{l}\text { Leucocytes }(\mathrm{K} / \mu \mathrm{L}) \\
(4.5-13.5)\end{array}$ & 16.1 & 4.7 & 20.3 \\
\hline $\begin{array}{l}\text { Platelets }(\mathrm{K} / \mu \mathrm{L}) \\
(140-440)\end{array}$ & 252 & 86 & 243 \\
\hline $\begin{array}{l}\text { Neutrophils }(\mathrm{K} / \mu \mathrm{L}) \\
(1.30-9)\end{array}$ & 13.68 & 4.42 & 16.04 \\
\hline $\begin{array}{l}\text { Lymphocytes }(\mathrm{K} / \mu \mathrm{L}) \\
(1.90-7.5)\end{array}$ & 1.45 & 0.09 & 2.23 \\
\hline $\begin{array}{l}\text { C-reactive protein }(\mathrm{mg} / \mathrm{L}) \\
(<9.9)\end{array}$ & 202.4 & 213 & 284.4 \\
\hline $\begin{array}{l}\text { Erythrocyte } \\
\text { sedimentation rate }(\mathrm{mm} / \\
\text { hour })(0-20)\end{array}$ & 46 & 56 & 50 \\
\hline $\begin{array}{l}\text { Fibrinogen }(\mathrm{mg} / \mathrm{dL}) \\
(183-503)\end{array}$ & 640 & 501 & 495 \\
\hline $\begin{array}{l}\text { D-dimers }(\mathrm{mcg} / \mathrm{mL}) \\
(\leq 0.5)\end{array}$ & 2.98 & 17.82 & 4.29 \\
\hline Ferritin (ng/ml) (13-145) & 203 & 490 & 2574 \\
\hline Albumin $(\mathrm{g} / \mathrm{dL})(3.8-5.4)$ & 3.0 & 2.5 & 3.4 \\
\hline $\begin{array}{l}\text { Creatinine }(\mathrm{mg} / \mathrm{dL})(0.6 \\
\text { to } 1.3)\end{array}$ & 0.56 & 0.62 & 2.08 \\
\hline $\begin{array}{l}\text { Troponin }(\mathrm{ng} / \mathrm{mL}) \\
(0.00-0.030)\end{array}$ & 0.539 & 0.274 & 1.456 \\
\hline $\begin{array}{l}\text { B-type natriuretic peptide } \\
(\mathrm{pg} / \mathrm{mL})(1-100)\end{array}$ & 396 & 1213 & 383 \\
\hline Chest imaging & Not done & $\begin{array}{c}\text { Chest CT scan: bilateral } \\
\text { infiltrates with small pleural } \\
\text { effusion }\end{array}$ & Chest radiograph: Bilateral infiltrates \\
\hline $\begin{array}{l}\text { Transthoracic } \\
\text { echocardiographic } \\
\text { findings }\end{array}$ & $\begin{array}{c}\text { Hyperdynamic left } \\
\text { ventricular systolic function; } \\
\text { shortening fraction of } 43.7 \%\end{array}$ & $\begin{array}{c}\text { Hyperdynamic left } \\
\text { ventricular systolic function; } \\
\text { shortening fraction of } 40 \%\end{array}$ & $\begin{array}{c}\text { Borderline low systolic function with a } \\
\text { shortening fraction of } 29-30 \% \text {. No coronary } \\
\text { artery ectasia or aneurysms. No evidence of } \\
\text { pulmonary hypertension. Trivial pericardial } \\
\text { effusion. } \\
\text { Electrocardiography (EKG): nonspecific T- } \\
\text { wave changes and low-voltage QRS. }\end{array}$ \\
\hline $\begin{array}{l}\text { Duration of ICU stay } \\
\text { (days) }\end{array}$ & 4 & 12 & 6 \\
\hline
\end{tabular}

neurological), with positive testing for SARS-CoV-2 indicating current or recent infection or COVID-19 exposure; and no other alternative plausible diagnoses [4].

All of our patients presented with multisystem disease with elevated inflammatory markers, consistent with the CDC case definition of MIS-C. Testing to detect SARS-CoV2 infection was positive in all patients. The report from Italy described positive testing by RT-PCR (reverse-transcription polymerase chain reaction) and/or serology for SARS-CoV2 similar to our observation [7], although in the study from the UK, all children were antibody positive [5]. Evaluation for other infectious agents was negative.
All of our patients had circulatory shock requiring inotropic support and all had elevated BNP and troponin levels, similar to study from the UK. [5]. However, one of our patients presented with neurologic involvement which has not been observed in published reports thus far.

Majority of the children in reports thus far showed recovery with response to varying degrees of intensive care, with most requiring respiratory support, inotropes, IVIG (intravenous immunoglobulin) and steroids [5-7], as seen in our patients. One of our patients received tocilizumab unlike any of the previous reports of MIS-C. Interleukin-6 inhibitors may be beneficial given the cytokine storm 
associated with COVID-19; however, their role in treatment of MIS-C needs to be further investigated. None of the children died in this report similar to the study from Italy [7], and all of the children showed recovery and are being followed up for long-term complications.

Clinical presentation of MIS-C with multiorgan involvement and elevated inflammatory markers may have overlapping features with Kawasaki disease and toxic shock syndrome, but is presently understood to be a separate phenomenon. MIS-C is thought to be related to a post-viral immune-mediated inflammatory process, as suggested by recognition of clinical cases as we move into post-peak phase of COVID-19 illness incidence, although the pathogenesis of the syndrome remains largely unclear [4].

\section{Conclusion}

We observed multisystem inflammatory syndrome in children (MIS-C) in three previously healthy patients with SARS-CoV-2 infection, all of whom became critically ill with multisystem involvement. SARS-CoV-2 associated MIS-C requires further investigation. As knowledge about novel manifestations of COVID-19 in children is evolving, reporting is essential to better equip clinicians in recognizing the spectrum of symptoms of MIS-C, which is imperative for timely initiation of appropriate management.

\section{Abbreviations}

MIS-C: Multisystem inflammatory syndrome in children RT-PCR: Reverse transcription polymerase chain reaction BNP: B-type natriuretic peptide.

\section{Data Availability}

All data generated or analyzed during this clinical case report are included within this article.

\section{Disclosure}

Helen Kest and Ashlesha Kaushik contributed equally as cofirst authors.

\section{Conflicts of Interest}

The authors have no conflicts of interest relevant to this article to disclose.

\section{References}

[1] X. Lu, L. Zhang, Chinese Pediatric Novel Coronavirus Study Team et al., "SARS-CoV-2 infection in children," New England Journal of Medicine, vol. 382, no. 17, pp. 1663-1665, 2020.

[2] Y. Dong, X. Mo, Y. Hu et al., "Epidemiology of COVID-19 among Children in China," Pediatrics, vol. 145, no. 6, Article ID e20200702, 2020.

[3] CDC COVID-19 Response Team, "Coronavirus disease 2019 in children-United States, February 12-April 2, 2020," Morbidity and Mortality Weekly Report (MMWR), vol. 69, no. 14, pp. 422-426, 2020.
[4] Centers for Disease Control and Prevention (CDC), "Health advisory on multisystem inflammatory syndrome in children (MIS-C) associated with coronavirus disease 2019," 2019, https://emergency.cdc.gov/han/2020/han00432.asp? deliveryName=USCDC_511-DM28431.

[5] S. Riphagen, X. Gomez, C. Gonzales-Martinez, N. Wilkinson, and P. Theocharis, "Hyperinflammatory shock in children during COVID-19 pandemic," The Lancet, vol. 395, no. 10237, pp. 1607-1608, 2020.

[6] Royal College of Paediatrics and Child Health Guidance, "Paediatric multisystem inflammatory syndrome temporally associated with COVID-19," 2020, https://www.rcpch.ac.uk/ sites/default/files/2020-05/COVID-19-Paediatricmultisystem-\%20inflammatory\%20syndrome-20200501.pdf.

[7] L. Verdoni, A. Mazza, A. Gervasoni et al., "An outbreak of severe Kawasaki-like disease at the Italian epicentre of the SARS-CoV-2 epidemic: an observational cohort study," The Lancet, vol. 395, no. 10239, pp. 1771-1778, 2020. 